\title{
RELATIONSHIP BETWEEN EXTERNAL WEATHER CONDITIONS AND NUMBER OF HIBERNATING BATS IN TWO CAVES IN THE WESTERN ITALIAN ALPS
}

\author{
ROBERTO TOFFOLI ${ }^{1}$ \\ ${ }^{1}$ Chirosphera Association for the study and protection of Bats and the environment \\ Via Tetti Barbiere 11, 10128 Santena TO, Italy \\ e-mail corresponding author: rtoffoli@iol.it
}

\begin{abstract}
.
Weather conditions can influence the hibernation behaviour of temperate cave-dwelling bats that are tolerant to low temperatures, and their number can be correlated with weather variables. In this work a first assessment on the correlation between the number of individuals of three species of hibernating bats (Barbastella barbastellus, Myotis emarginatus and Rhinolophus hipposideros) and the environmental weather conditions before the survey was carried out is provided for two hibernacula of the Italian Western Alps.

For the B. barbastellus, a significant inverse correlation was observed between the number of bats detected and the average daily temperature for thirty days preceding the count $(p=0.036)$ and ten days before counting $(p=0.036)$. A significant positive correlation was observed for $\mathrm{M}$. emarginatus between the number of individuals and the average daily temperatures for thirty days preceding the count $(p=0.018)$. For $\mathrm{R}$. hipposideros, a significant inverse correlation was observed with the average daily temperatures for the ten days before the count $(p=0.048)$ and the differences in the maximum and minimum temperature of the ten days preceding the count $(p=0.002)$.

Results of this study show how the ambient temperatures before a count can influence the number of bats present in hibernacula. This confirms how the abundance of bats at underground hibernating sites can be used as an indicator of climate change, as temperature is an important factor controlling hibernation, although further studies are needed in order to better evaluate how the climatic variables interact with each other in regulating the number of bats in the hibernacula.
\end{abstract}

Key words: Chiroptera, hibernaculum, annual changes, climatic variable, temperate bats

\section{INTRODUCTION}

A characteristic feature of the annual cycle of insectivorous temperate zone bats is hibernation (Altringham, 2011). Selection of a suitable hibernation site is crucial for overwinter survival, and caves and mines are the most common type of hibernacula. Hibernation is usually interrupted by periodical arousals. Such arousals may involve hibernation site switching, drinking, feeding, or even mating (Ransome, 1971; Daan, 1973; Speakman \& Racey, 1989).

For temperate cave-dwelling bats, one of the monitoring methods normally used is counting hibernating bats in their hibernacula (Battersby 2010). Several surveys based on this kind of winter censuses have been performed in Europe, in some cases for decades (e.g. Daan et al. 1980; Horáček 2010; Uhrin et al. 2010; Ingersoll et al. 2013; Piksa \& Nowak 2013; Kerbiriou et al. 2018, Toffoli \& Calvini 2021). This method is simple, facilitates comparisons among datasets, and is the most common and widespread source of bat data in Europe. It has been used for the definition of a prototype indicator of trends in European bat populations (Van der Meij et al. 2015).
However, this method is not free from bias: for many species the relationship between the number of bats seen and the number of bats present is uncertain (Battersby 2010, Zukal et al., 2017), and there is some evidence for changes in abundance and winter activity (Daan 1973; Berková \& Zukal 2010; Zukal et al., 2017; Toffoli 2019). The weather conditions can influence the hibernation behaviour of bat species that are tolerant to low temperatures. In Germany, for example, a strong dependence between the number of hibernating Barbastella barbastellus and Myotis nattereri bats and the temperatures the days before the counting survey has been observed. Low numbers of these bats were seen in hibernacula when temperatures were several (5-10) degrees above $0^{\circ}$ $\mathrm{C}$; conversely, much higher numbers were detected when temperatures just around or below zero were seen (Battersby 2010). Some species of cryophilic bats that hibernate at lower temperatures, such as $B$. barbastellus, are particularly sensitive to temperature changes (Rydell \& Bogdanowicz 1997; Rebelo et al. 2010). During hibernation, this species occupies structures with temperatures comprised between 
$-3^{\circ} \mathrm{C}$ and $+6.5^{\circ} \mathrm{C}$ (Rydell \& Bogdanowicz 1997; Weeb et al. 1995; Jurczyszyn et al. 2003), but usually only slightly exceeding $0^{\circ} \mathrm{C}$, with either strong airflow or frost (Sachanowicz \& Zub 2002; Fuszara et al. 2003). Research has shown a pronounced effect of ambient temperature on the total winter energy requirements of bats, including $B$. barbastellus. A relatively narrow combination of hibernaculum temperature and winter length permits a successful hibernation (Stawski et al. 2014), whereas hibernating at warmer temperatures leads to increased energy expenditure (Geiser 2004; Boyles et al. 2007). To mitigate the potential costs of warmer winters, some bats that hibernate at low temperatures can modify their behaviour (Sachanowicz \& Zub 2002). In some hibernacula in Poland, changes in mean outside temperature accounted for $91 \%$ of changes to the air temperature inside; the mean number of $B$. barbastellus was related to mean air temperature, and the bats appeared in the hibernacula when the mean monthly temperature dropped below $0^{\circ} \mathrm{C}$ in late November or during December (Sachanowicz \& Zub 2002). This species usually arrives in large hibernacula gradually, probably leaving other roost types only after the temperature inside drops below a certain point (Gottfried et al. 2020). However, given different needs in the temperature of the hibernacula by the different species (Webb et al. 1995), the behaviour to changes in environmental climatic variables may be different.

The increase in temperatures and the reduction of cold periods shown in the western Alps in recent decades (Acquaotta et al. 2015) can therefore generate variations in the number of bats of different species present in hibernation in this area. This could be related to the decrease in their density recently observed in some hibernacula (Toffoli 2019). The aim of this work is to provide a first assessment on the correlation between the number of individuals of three species of hibernating bats and the environmental weather conditions before the survey was carried out in two hibernacula of the Italian Western Alps.

\section{Materials ANd Methods}

For this analysis, we used the counts of hibernating bats in two hibernacula of the Italian Western Alps, distant from each other about $80 \mathrm{~km}$ : Rio Martino cave at 1530 meters above sea level with an internal temperature of about $4^{\circ} \mathrm{C}$ (Badino 2008) and Le Vene cave at 1558 meters above sea level with an internal temperature of about $6^{\circ} \mathrm{C}$ (D. Barberis, unpublished data). In Rio Martino cave, 12 bat species were present in winter, and the most abundant species was B. barbastellus, which represented $91.2 \%$ of the total hibernating bats present, followed by Myotis emarginatus (Toffoli 2019). In the Le Vene cave, 9 bat species were present in winter, and the most abundant species was Rhinolophus hipposideros, which represented $96.7 \%$ of the total hibernating bats counted (R. Toffoli, unpublished data).

The two hibernacula have been monitored regularly for 30 years (Table 1) by counting the hibernating bats one time for season between the last five days of December and the first ten days of February, as recommended by Battersby (2010). Only for the Rio Martino cave in the last four winters two counts were made: one in the first ten days of January and the other in the first ten days of February. In this case, both the two counts were used for analysis. For the analysis, only the data of the most abundant species were used: B. barbastellus and M. emarginatus for the Rio Martino cave and R. hipposideros for the Le Vene cave. B. barbastellus showed a positive trend in the long term with an average annual increase of $14.8 \%$ with a trend reversal in the last ten years (average annual decrease of $-10.9 \%$ ), while M. emarginatus showed a trend positive in the long term (average annual increase of $8.7 \%$ ) even more evident in the last ten years (average annual increase of $30.3 \%$ ). $R$. hipposideros has shown a positive trend in the long term with an average annual increase of 3.7\% with a trend reversal in the last ten years (average annual decrease of $-2.3 \%$ ) (Toffoli 2019; R. Toffoli, unpublished data).

The bat counting data were correlated with climatic variables obtained from two weather stations, respectively, located in Crissolo $(0.7 \mathrm{~km}$ from Rio Martino cave, period from 2004 to 2021) and Upega (3.3 km from le Vene cave, period from 1997-2021) and were available online on the website of the Regional Agency for Environmental Protection - Piedmont Region (https://www.arpa.piemonte.it/rischinaturali/accesso-ai-dati/annali_meteoidrologici/ annali-meteo-idro/banca-dati-meteorologica.html). The climatic variables available are listed in Table 2.

When analyzing the relationships between the number of hibernating bats and climatic variables, temporal trends were detrended prior to analysis (Lindström \& Forchhammer 2010) using the function "remove trend" of the Past software 3.22 (Hammer et al. 2001). The correlation between bat number and climatic variables was carried out by univariate methods using Pearson's correlation. In addition to 
Roberto Toffoli - External Weather Conditions and the Number of Hibernating Bats

Table 1: Maximum number of hibernating bats counted in the two caves.

\begin{tabular}{|c|c|c|c|}
\hline & \multicolumn{2}{|c|}{ Rio Martino cave } & \multirow[b]{2}{*}{ Rhinolophus hipposideros } \\
\hline $\begin{array}{l}\text { Hibernating } \\
\text { period }\end{array}$ & Barbastella barbastellus & Myotis emarginatus & \\
\hline 1991/1992 & 7 & 2 & 66 \\
\hline $1992 / 1993$ & 10 & 2 & 118 \\
\hline 1993/1994 & 11 & 1 & 100 \\
\hline $1994 / 1995$ & 10 & 1 & 122 \\
\hline $1995 / 1996$ & 10 & 1 & 186 \\
\hline $1996 / 1997$ & 17 & 1 & 180 \\
\hline $1997 / 1998$ & 18 & 2 & 230 \\
\hline $1998 / 1999$ & 16 & 2 & 251 \\
\hline $1999 / 2000$ & 21 & 2 & 273 \\
\hline $2000 / 2001$ & 41 & 4 & 337 \\
\hline $2001 / 2002$ & 44 & 5 & 282 \\
\hline $2002 / 2003$ & 76 & 2 & 388 \\
\hline $2003 / 2004$ & 82 & 1 & 308 \\
\hline $2004 / 2005$ & 129 & 2 & 321 \\
\hline $2005 / 2006$ & 178 & 9 & 444 \\
\hline $2006 / 2007$ & 183 & 6 & 482 \\
\hline $2007 / 2008$ & 272 & 3 & 446 \\
\hline $2008 / 2009$ & 295 & 3 & 389 \\
\hline $2009 / 2010$ & 375 & 1 & 466 \\
\hline $2010 / 2011$ & 380 & 4 & 297 \\
\hline $2011 / 2012$ & 367 & 2 & 317 \\
\hline $2012 / 2013$ & 399 & 6 & 473 \\
\hline $2013 / 2014$ & 410 & 5 & 372 \\
\hline $2014 / 2015$ & 380 & 5 & 298 \\
\hline $2015 / 2016$ & 170 & 3 & 315 \\
\hline $2016 / 2017$ & 278 & 7 & 310 \\
\hline $2017 / 2018$ & 193 & 19 & 349 \\
\hline $2018 / 2019$ & 195 & 18 & 368 \\
\hline $2019 / 2020$ & 117 & 30 & 287 \\
\hline $2020 / 2021$ & 201 & 21 & 299 \\
\hline
\end{tabular}

Table 2: Abbreviations of climatic variables used in the text.

\begin{tabular}{|c|c|}
\hline Variable & Description \\
\hline T_aveg_30 & Mean daily ambient temperature for the 30 days preceding the count $\left(\right.$ in ${ }^{\circ} \mathrm{C}$ ) \\
\hline T_aveg_10 & Mean daily ambient temperature for the 10 days preceding the count (in ${ }^{\circ} \mathrm{C}$ ) \\
\hline Tmax-Tmin_10 & $\begin{array}{l}\text { Mean of values of the difference between } \mathrm{T} \max \text { (maximum daily temperature) and } \mathrm{T} \text { min } \\
\text { (minimum daily temperature) of the } 10 \text { days preceding the count (in }{ }^{\circ} \mathrm{C} \text { ) }\end{array}$ \\
\hline T_min_1 & Minimal temperature of the day preceding the count $\left(\right.$ in ${ }^{\circ} \mathrm{C}$ ) \\
\hline Rainfall 10 & Rainfall in $\mathrm{mm}$ for the 10 days preceding the count \\
\hline
\end{tabular}


climatic variables, the counting date has also been considered in the analysis, measured as the number of days after December 26, in order to evaluate a possible effect on the number of bats.

\section{RESULTS}

For each of the three species included in the analysis, the number of bats observed was correlated with the average daily temperature, while no correlation was observed with the counting date. In particular for B. barbastellus, a significant inverse correlation was observed between the number of bats detected and the average daily temperature from the thirty days preceding the count (T_aveg_30: Pearson correlation $=-0.460 ; \mathrm{p}=0.036)$ and ten days before counting (T_aveg_10: Pearson correlation $=-0.459 ; \mathrm{p}=$ 0.036) (Table 3, Fig.1). A significant inverse correlation with the average daily temperatures of the ten days before the count was also observed for $R$. hipposideros (T_aveg_10: Pearson correlation $=-0.399$; $\mathrm{p}=0.048$ ) (Table 3; Fig.1), while no correlation was observed with the averages of the daily temperatures from the thirty days before the count (Tab.3). For $M$. emarginatus, a significant positive correlation was observed only between the number of individuals and the average daily temperatures of the thirty days preceding the count ( $\mathrm{T} \_$aveg_30: Pearson correlation $=0.512 ; \mathrm{p}=0.018$ ) (Table 3; Fig. 1 ).

The other variables considered were not correlated with the number of bats observed for any of the three species, with the exception of the average of the differences between the maximum and minimum temperature from the ten days preceding the count, which is inversely correlated with the number of $R$. hipposideros observed (Tmax-Tmin_10: Pearson correlation $=-0.579 ; p=0.002)($ Table $3 ;$ Fig. 1$)$.

\section{Discussion ANd Conclusion}

Results of this study show how the ambient temperatures before the count can influence the number of bats present in the monitored hibernacula. These results are in line with what was observed in other studies examining the influence of environmental climatic variables on the activity of bats in winter (Berková \& Zukal 2010). The ambient temperature is a key climatic factor influencing not only seasonal changes in activity but also the night-to-night flight activity patterns of temperate zone bats. In particular, this correlation also influences the timing of hibernation (Erkert 1982). During hibernation, the main relationship between activity and ambient climatic variables is the daily average temperature (Daan 1973; Berková \& Zukal 2010), which is thought to be a crucial exogenous factor controlling seasonal timing and the course of hibernation (e.g. torpor bout duration) (Erkert 1982; Park et al. 2000). A similar correlation is known for the difference between maximum and minimum temperature (Berková \& Zukal 2010). A positive relationship between activity and the difference between maximum and minimum temperature suggests that a higher temperature fluctuation during the day combined with a daily average temperature $>0^{\circ}$ induces arousal, and more bats become active (Berková \& Zukal 2010). This correlation could explain our results that show an increase in the number of bats present in the hibernacula when the average environmental temperatures and the difference between maximum and minimum temperature lowers, at least for B. barbastellus and R. hipposideros. With higher ambient temperatures, an increased flight activity and more frequent roost switching behaviour is expected. Roost switching is known for some species (e.g. Rhinolophus ferrumequinum, Myotis daubentonii, M. nattereri) also during the winter months

Table 3: Correlation with the external climatic variable in the number of hibernating bats.

\begin{tabular}{llccc} 
& & $\begin{array}{c}\text { Barbastella } \\
\text { barbastellus }\end{array}$ & $\begin{array}{c}\text { Myotis } \\
\text { emarginatus }\end{array}$ & $\begin{array}{c}\text { Rhinolophus } \\
\text { hipposideros }\end{array}$ \\
\hline T_aveg_30 & Pearson's r & $-0.460 *$ & $0.512 *$ & -0.149 \\
T_aveg_10 & p-value & 0.036 & 0.018 & 0.477 \\
Tmax-Tmin_10 & Pearson's r & $-0.459 *$ & 0.410 & $-0.399 *$ \\
T_min_1 & p-value & 0.036 & 0.065 & 0.048 \\
Tainfall_10 & Pearson's r & 0.135 & 0.199 & $-0.579 * *$ \\
R-value & 0.559 & 0.132 & 0.002 \\
\hline$*$
\end{tabular}

$* \mathrm{p}<.05, * * \mathrm{p}<.01, * * * \mathrm{p}<.001$ 

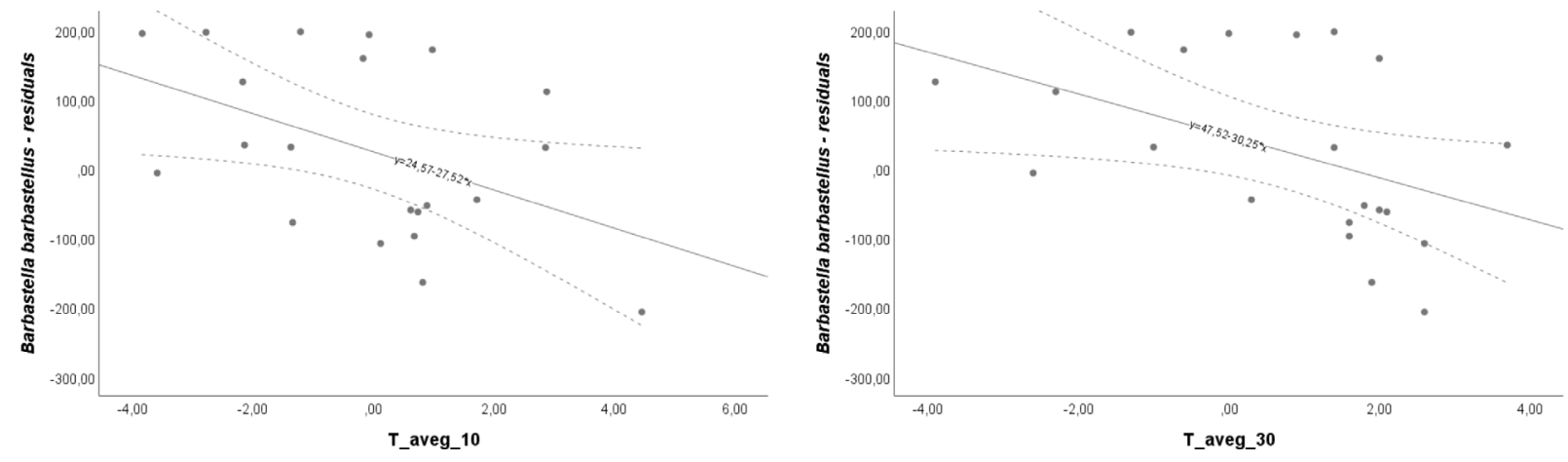

A

B
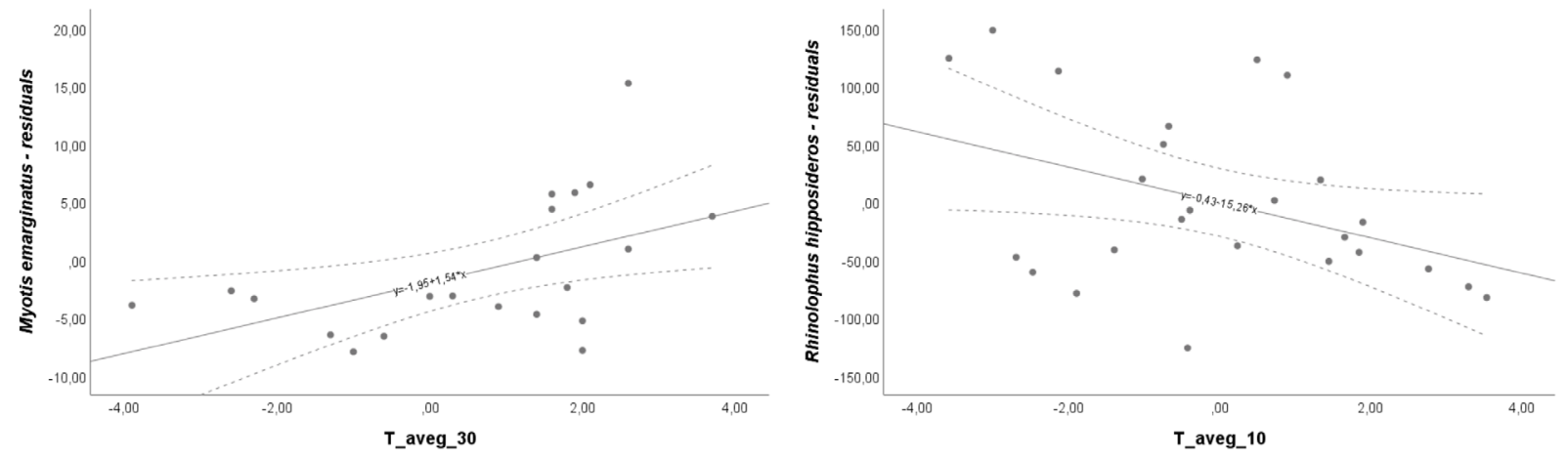

C

D

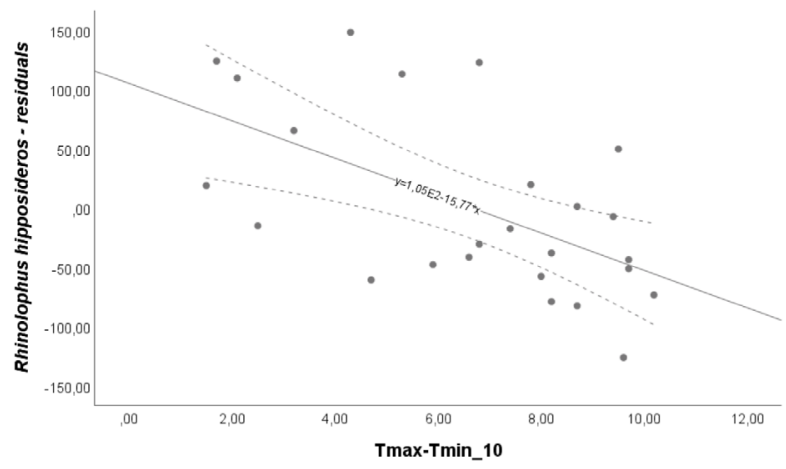

E

Figure 1: Relationships between the number of hibernating bats and the significant climatic variables tested in Table $3(\mathrm{~A}=$ correlation of the number of $B$. barbastellus with $\mathrm{T}$ aveg $10 ; \mathrm{B}=$ correlation of the number of $B$. barbastellus with T_aveg_30; $\mathrm{C}=$ correlation of the number of $M$. emarginatus with $\mathrm{T}$ aveg_30; $\mathrm{D}=$ correlation of the number of $R$. hipposideros with T_aveg_10; $\mathrm{E}=$ correlation of the number of $R$. hipposideros with Average Tmax-Tmin_10).

(Daan 1973, Ransome 1990), probably as a response to unsuitable conditions in some roosts (Sendor \& Simon 2003). Moreover, it is probable that B. barbastellus begins hibernation in smaller, shallower sites, which cool more rapidly, delaying their arrival in larger underground roosts (Gottfried et al. 2020). This species usually arrives in large hibernacula gradually, probably leaving other roost types only after the temperature inside drops below a certain point. During a study in central Poland, the number of $B$. barbastellus (counted every two weeks) increased until the end of January, and in January some individuals were hibernating in tree crevices or in an outside firewood stack. Temperatures in January may exert a remarkable effect on the number of $B$. barbastellus in large hibernacula (Gottfried et al. 2020). Frost 
spells, depending on their duration and/or minimum temperatures, may flush different numbers of individuals out of shallow roosts, thus affecting the results of censuses (Gottfried et al. 2020). On the other hand, the positive correlation we found between average ambient temperatures and the number of hibernating $M$. emarginatus could be explained with the choice of temperature in hibernation sites and with energy saving requirements during hibernation. This species prefers hibernacula with a temperature range between $5^{\circ} \mathrm{C}$ and $10^{\circ} \mathrm{C}$ degrees (Webb et al 1995), preferably between $7^{\circ} \mathrm{C}$ and $10.4^{\circ} \mathrm{C}$ (Kowalski 1953; Daan \& Wichers 1968). Previous studies showed that bats declined in body mass more rapidly early in the season when ambient temperature in hibernaculum was higher. The rate of estimated fat consumption decreased as hibernation progressed and as the ambient temperature declined within the hibernaculum (Lesiński 1986; Jonasson \& Willis 2012). Even if a correlation between the internal temperature of a hibernaculum and the external ambient temperature is reported (Speakman \& Racey 1986) for alpine caves, in general if the cave temperature is above zero and the region of infiltration is covered by snow, a warm climatic episode during winter could provoke a cave cooling (Badino 2010), making the site more suitable for hibernation with less energy expenditure; it could be convenient for $M$. emarginatus to switch to the site to conclude hibernation in order to save as much energy as possible.

In recent decades, an increase in winter temperatures and a reduction of cold periods in the Italian western Alps was observed (Acquaotta et al. 2015), and this could favour the species less sensitive to the low temperatures in the large hibernacula to hibernate in smaller and shallower sites (e.g B. barbastellus). At the same time, the large hibernacula with colder and constant temperatures could be more frequented by species with higher thermal needs (e.g. M. emarginatus). This hypothesis could therefore, in part, explain the recent changes in the number of hibernating bats in the two caves when taking into consideration a decrease in B. barbastellus and an increase in M. emarginatus.

Despite preliminary results from only few species and two hibernation sites, the correlation between winter environmental climatic variables and the number of hibernating bats appears evident. This confirms how the abundance of bats at underground hibernating sites in Europe can be used as an indicator of climate change, as temperature is an important factor controlling hibernation (Newson et al. 2009). However, further studies are needed in order to better evaluate how the climatic variables interact with each other in regulating the number of bats in the hibernacula and how they can influence the possible changes in the aggregation behaviours (e.g. hibernation in clusters or isolates) and choice of shelters.

\section{ACKNOWLEDGEMENTS}

We thank all the collaborators for their help with fieldwork in particular D. Barberis, P. Culasso. Thanks also to M. Meregalli (Università degli Studi di Torino), M. Cucco (Universita' del Piemonte Orientale, DISIT) for insightful comments on a previous draft of this paper.

\section{REFERENCES}

Altringham, J.D. (2011) Bats: from evolution to conservation. Oxford: Oxford University Press

Acquaotta, F., Fratianni, S. \& Garzena, D. (2015) Temperature changes in the North-Western Italian Alps from 1961 to 2010. Theor Appl Climatol, 122(3-4), 619-634. https://doi.org/10.1007/ s00704-014-1316-7

Badino, G. (2010). Underground meteorology-"What's the weather underground?". Acta carsologica, 39(3), 427-448. https://doi. org/10.3986/ac.v39i3.74

Battersby, J. (2010) Guidelines for surveillance and monitoring of European bats. EUROBATS Publication Series (no. 5). Bonn, Germany: UNEP/ EUROBATS Secretariat

Berková, H. \& Zukal, J. (2010). Cave visitation by temperate zone bats: effects of climatic factors. J. Zool, 280(4), 387-395. https://doi.org/10.1111/ j.1469-7998.2009.00673.x

Boyles, J. G., Dunbar, M. B., Storm, J. J. \& Brack, V. (2007). Energy availability influences microclimate selection of hibernating bats. Journal of Experimental Biology, 210(24), 4345-4350. https://doi.org/10.1242/jeb.007294

Daan, S. (1973). Activity during natural hibernation in three species of vespertilionid bats. Neth. J. Zool, 23, 1-71. https://doi. org/10.1163/002829673X00193

Daan, S., Glas, G.H. \& Voute, A.M. (1980) Long term changes in bat populations in the Netherlands. Lutra, 22, 95-105

Daan, S. \& Wichers, H. J. (1968) Habitat selection of bats hibernating in a limestone cave. Zeitschrift für Säugetierkunde, 33, 262-287. 
Fuszara, E., Fuszara, M., Jurczyszyn, M., Kowalski, M., Lesiński, G., Paszkiewicz R, et al. (2003) Shelter preference of the barbastelle, Barbastella barbastellus (Schreber, 1774), hibernating in Poland. Nyctalus, 8, 528-535.

Geiser, F. (2004). Metabolic rate and body temperature reduction during hibernation and daily torpor. Annu. Rev. Physiol., 66, 239-274. https://doi. org/10.1146/annurev.physiol.66.032102.115105

Gottfried, I., Gottfried, T., Lesiński, G., Hebda, G., Ignaczak, M., Wojtaszyn, G., et al.. (2020). Longterm changes in winter abundance of the barbastelle Barbastella barbastellus in Poland and the climate change-Are current monitoring schemes still reliable for cryophilic bat species?. PloS one, 15(2), e0227912. https://doi.org/10.1371/ journal.pone.0227912

Erkert, H. G. (1982) Ecological aspects of bat activity rhythms. In: T. H. Kunz (Ed.), Ecology of bats (pp. 201-242). Boston, Massachusetts: Springer.

Hammer, Ø., Harper, D. A. \& Ryan, P. D. (2001). PAST: Paleontological statistics software package for education and data analysis. Palaeontologia electronica, 4(1), 9.

Horáček, I. (2010) Monitoring bats in underground hibernacula. In: I., Horáček \& M.,Uhrin (Eds.) A tribute to bats (pp. 93-108). Lesnická Práce, s.r.o, Kostelec nad Černými lesy.

Jonasson, K.A. \& Willis, C.K.R. (2012) Hibernation energetics of free-ranging little brown bats. J. Exp. Biol., 215(12), 2141-2149. https://doi. org/10.1242/jeb.066514 PMID: 22623203

Jurczyszyn, M., Bajwolski, T, Dezor, L., Dzięciołowski, R., Dąbrowska, A. \& Diskorz, R. (2003) Some ecological aspects and threats for population of Barbastella barbastellus hibernating in Poznan (Poland). Nyctalus, 8, 610-614.

Kerbiriou, C., Bas, Y., Julien, J.F. \& groupes Chiroptères SFEPM (2018) Estimations des tendances des populations de Chiroptères à partir des suivis de gîtes hivernaux. Symbioses, 37, 7 - 15.

Kowalski, K. (1953) Materialy do rozmieszczenia i ekologii nietoperzy jaskiniowych v.' Polsce. Fragm. faun. Mus. zool. Pol., 6 (21), 541-567 (with a summary in english).

Ingersoll, T.E., Sewall, B.J. \& Amelon, S.K. (2013) Improved analysis of long-term monitoring data demonstrates marked regional declines of bat populations in the eastern United States. PLoSOne, 8(6), e65907. DOI: 10.1371/journal. pone.0065907

Lesiński, G.(1986) Ecology of bats hibernating underground in Central Poland. Acta Theriol., 31, 507-531.

Lindström, J. \& Forchhammer, M.C. (2010) Time-series analyses. In: A.P. Møller, W. Fiedler, P. Berthold (Eds), Effects of climate change on birds (57-66). Oxford : Oxford University Press.

Newson, S. E., Mendes, S., Crick, H., Dulvy, N., Houghton, J., Hays, G. C., et al. (2009) Indicators of the impact of climate change on migratory species. Endanger. Species Res., 7(2), 101-113. https://doi.org/10.3354/esr00162

Park, K. J., Jones, G. \& Ransome, R. D. (2000). Torpor, arousal and activity of hibernating greater horseshoe bats (Rhinolophus ferrumequinum). Functional ecology, 14(5), 580-588. https://doi. org/10.1046/j.1365-2435.2000.t01-1-00460.x

Piksa, K. \& Nowak, J. (2013) The bat fauna hibernating in the caves of the Polish Tatra Mountains, and its long-term changes. Open Life Sciences, 8, 448-460. https://doi.org/10.2478/s11535-0130146-9

Ransome, R.D. (1971) The effect of ambient temperature on the arousal frequency of the hibernating greater horseshoe bat, Rhinolophus ferrumequinum, in relation to site selection and the hibernation state. J. Zool., 164, 353-371. https://doi. org/10.1111/j.1469-7998.1971.tb01323.x

Ransome, R. (1990) Hibernating Bats. London: Christopher Helm.

Rebelo, H., Tarroso, P. \& Jones, G. (2010) Predicted impact of climate change on European bats in relation to their biogeographic patterns. Glob Change Biol., 16, 561-576. https://doi. org/10.1111/j.1365-2486.2009.02021.x

Rydell, J. \& Bogdanowicz, W. (1997) Barbastella barbastellus. Mammalian Species, 557, 1-8. https://doi. org/10.2307/3504499

Sachanowicz, K. \& Zub, K. (2002) Numbers of hibernating Barbastella barbastellus (Schreber, 1774) (Chiroptera, Vespertilionidae) and thermal conditions in military bunkers. Mamm Biol., 67, 179-184. https://doi.org/10.1078/1616-504700026

Sendor, T. \& Simon, M. (2003) Population dynamics of the pipistrelle bat: Effects of sex, age and winter weather on seasonal survival. J. Anim. Ecol., 72(2), 308-320. https ://doi. org/10.1046/j.1365-2656.2003.00702.x 
Speakman, J..R. \& Racey, P.A. (1989). Hibernal ecology of the pipistrelle bat: energy expenditure, water requirements and mass loss, implications for survival and the function of emergence flights. J. Anim. Ecol. 58, 797-813.

Stawski, C., Willis, C. K. R. \& Geiser, F. (2014). The importance of temporal heterothermy in bats. Journal of Zoology, 292(2), 86-100. https://doi. org/10.1111/jzo.12105

Toffoli, R (2019) The bats of the Rio Martino Cave, North West Italy (Mammalia Chiroptera). Biodiversity Journal, 10, 249-257. https://doi. org/10.31396/Biodiv.Jour.2019.10.3.249.257

Toffoli, R. \& Calvini, M. (2021) Long term trends of hibernating bats in North-Western Italy. Biologia, 76(2), 633-643. https://doi.org/10.2478/ s11756-020-00584-x

Uhrin, M., Benda, P., Obuch, J. \& Urban, P. (2010) Changes in abundance of hibernating bats in central Slovakia (1992-2009). Biologia, 65, 349361. https://doi.org/10.2478/s11756-010-0020-z
Van der Meij, T., Van Strien, A.J., Haysom, K.A., Dekker, J., Russ, J., Biala, K., Bihari, Z., Jansen, E., Langton, S. et al. (2015) Return of the bats? A prototype indicator of trends in European bat populations in underground hibernacula. Mamm. Biol 80, 170-177. https://doi.org/10.1016/j.mambio.2014.09.004

Webb, P.I., Speakman, J.R. \& Racey, P.A. (1996) How hot is a hibernaculum? A review of the temperatures at which bats hibernate. Can J Zool, 74, 761-765. https://doi.org/10.1139/z96-087

Zukal, J., Berková, H. \& Řehák, Z. (2005) Activity and shelter selection by Myotis myotis and Rhinolophus hipposideros hibernating in the Kateřinská cave (Czech Republic). Mamm. Biol., 70(5), 271-281. https://doi.org/10.1016/j. mambio.2005.03.003

Zukal. J., Berková, H., Band’ouchová, H., Kováčová, V. \& Pikula, J. (2017) Bats and caves: activity and ecology of bats wintering in caves. In: S., Karabulut, M.C., Cinku, (Eds.) Cave investigation. (pp. 51-75). InTech, Rijeka. 